\title{
CONTRIBUIÇÃO DOS RECURSOS DIDÁTICOS NA EJA: UMA ANÁLISE A PARTIR DO ESTÁGIO SUPERVISIONADO
}

\author{
Jean Oliveira Campos*, Jardênio de Oliveira Marinho, Valda Ozeane Camara \\ Cassiano de Oliveira, Lediam Rodrigues Lopes Ramos Reinaldo \\ *E-mail: jeannolliveira@gmail.com \\ Universidade Estadual da Paraíba, Brasil \\ DOI: 10.15628/rbept.2020.8266
}

Artigo submetido em fev/2019 e aceito em jan/2020

\section{RESUMO}

Os recursos didáticos são importantes ferramentas que auxiliam na condução do processo de ensino e aprendizagem, fornecendo subsídios para a construção do conhecimento e atuando como mediadores da aprendizagem. Os materiais utilizados como recursos didáticos nas salas de aula são diversificados quanto à estrutura, composição, aplicação e formas de uso, encontrando, portanto, sua função didática nas formas como é trabalhado pelo professor. Os recursos didáticos encontram aplicações nos diversos segmentos da Educação Básica, no entanto, no campo da Educação de Jovens e Adultos (EJA) são escassos os trabalhos que analisam as contribuições destes para o processo de ensino-aprendizagem nesta modalidade de ensino. Diante do exposto, o presente trabalho versa sobre os resultados obtidos a partir do desenvolvimento do projeto de intervenção na experiência do Estágio Supervisionado II, do curso de Pedagogia, em uma turma EJA, no município de Esperança - PB, onde a temática escolhida consistiu na utilização de Recursos Didáticos como estratégia metodológica para tornar as aulas mais atrativas e dinâmicas. Nesse sentido, o artigo tem como objetivo apresentar as contribuições da utilização de Recursos Didáticos na Educação de Jovens e Adultos. Os recursos didáticos foram utilizados como atividade de fixação do conteúdo e como suporte para a realização de atividades propostas nas diversas disciplinas. Os resultados mostram maior interação entre os alunos, atenção, dinamização das aulas e aprendizagem significativa dos conteúdos abordados. Os recursos didáticos se mostraram ferramentas facilitadoras do processo de aprendizagem e agem motivando, despertando a curiosidade e estimulando o aluno no desenvolvimento das atividades.

Palavras-Chave: Recursos Didáticos; Educação de Jovens e Adultos; Estágio Supervisionado.

\section{CONTRIBUTION OF TEACHING RESOURCES IN YOUTH AND ADULT EDUCATION (YAE): AN ANALYSIS FROM THE SUPERVISED STAGE}

\begin{abstract}
The didactic resources are important tools that help in the conduction of the teaching and learning process, providing subsidies for the construction of knowledge and acting as mediators of learning. The materials used as didactic resources in the classrooms are diversified in structure, composition, application and forms of use, finding, therefore, its
\end{abstract}


didactic function in the forms as it is worked by the teacher. The didactic resources find applications in the different segments of Basic Education, however, in the field of Youth and Adult Education (YEA), there are few studies that analyze their contributions to the teachinglearning process in this teaching modality. In view of the above, the present work is about the results obtained from the development of the project of intervention in the experience of Supervised Stage II, of the Pedagogy course, in an YEA class, in the municipality of Esperança - PB, where the chosen theme consisted of use of Didactic Resources as a methodological strategy to make classes more attractive and dynamic. In this sense, the article aims to present the contributions of the use of Didactic Resources in Youth and Adult Education. The didactic resources were used as activity to fix the content and as support for carrying out activities proposed in the various disciplines. The results show greater interaction among the students, attention, dynamization of the classes and significant learning of the contents covered. The didactic resources proved to be tools that facilitate the learning process and act motivating, arousing curiosity and stimulating the student in the development of activities.

Keywords: Didactic Resources; Youth and Adult Education; Supervised

\section{INTRODUÇÃO}

Os recursos didáticos são importantes ferramentas que auxiliam na condução do processo de ensino e aprendizagem, fornecem subsídios para a construção significativa do conhecimento e atuam como mediadores da aprendizagem. Os materiais utilizados como recursos didáticos nas salas de aula são diversificados quanto à estrutura, composição, aplicação e formas de uso, encontrando, portanto, sua função didática nas formas como é trabalhado pelo professor e nos objetivos propostos com o planejamento da aula. Tais recursos são utilizados nos diversos segmentos que compõem à Educação Básica, tendo maior ênfase nos Anos Iniciais do Ensino Fundamental I, onde encontra aplicação nas diversas áreas do conhecimento.

São escassos os trabalhos que versam sobre a utilização de Recursos Didáticos na Educação de Jovens e Adultos (EJA), evidenciando um limitado número de trabalhos sobre estratégias didáticas nesta modalidade de ensino. É provável que tal fato aconteça em virtude da dificuldade de se pensar e estabelecer metodologias adequadas para a EJA, o caráter diversificado e subjetivo das turmas pode despertar a insegurança no professor, o que 0 impede de experimentar e fazer uso de novas experiências e possibilidades didáticas no processo de aprendizagem. Tendo em vista o público de jovens e adultos já carregar uma bagagem conhecimentos construídos no cotidiano, e buscarem um ensino como maior objetividade, dessa forma, podem enxergar os recursos didáticos como desnecessários e uma perda do tempo, por acreditarem não contribuir com a aprendizagem. Diante dessa realidade se faz necessário que o educador da EJA desconstrua essa visão limitada e apresente as possibilidades didáticas e função facilitadora da aprendizagem que os Recursos Didáticos podem representar. 
Nas séries iniciais do Ensino Fundamental, os recursos são visto como estratégias que facilitadoras do processo de aprendizagem, pois fornecem melhorias na relação do professor com o aluno, na mediação do conhecimento, no desenvolvimento cognitivo do aluno, nos momentos de socialização e na apropriação do conhecimento (SILVA, et al., 2017). A maior parte dos trabalhos com ênfase em recursos didáticos se deram a partir de experiências de estágio ou revisão de literatura, com foco no Ensino Fundamental II e Ensino Médio, sendo o primeiro segmento do Ensino Fundamental, mais escasso quanto aos trabalhos com abordagem para os recursos didáticos. O Ensino Fundamental I corresponde ao $1^{\circ}$ Ciclo da EJA, os chamados "Anos Iniciais", é nesse segmento que se insere a realidade do presente trabalho.

Em se tratando da abordagem com recursos didáticos na modalidade EJA, Paiva (2016) chama atenção para a necessidade do trabalho com estes materiais ser aperfeiçoado através da prática docente, adaptando os usos para a realidade das turmas de EJA, ao passo que tais recursos permitem a construção do conhecimento significativo e em determinadas situações podem até mesmo substituir a figura do professor, e assim possam contribuir de forma ampla para as práticas de ensino nesta modalidade. A escolha dos recursos adequados para abordar determinados conteúdos na sala de aula é de fundamental importância pois permite ao professor aproveitar todas as possibilidades possíveis e favorecer a aprendizagem dos alunos e a interação entre estes (CORDEIRO; BARCELLOS, 2015; SILVA et al., 2017), caso contrário, pode acabar por dificultar o desenvolvimento da aula e esvaziar sua função didática.

Nesse contexto, o presente trabalho apresenta a experiência de Estágio Supervisionado II do curso Pedagogia, do Centro Universitário UNINTA, realizado em uma turma de EJA, em uma escola pública na zona rural do município de Esperança - PB. O projeto de intervenção desenvolvido consistiu na utilização de Recursos Didáticos como estratégia metodológica para tornar as aulas mais atrativas e dinâmicas, e consequentemente contribuir para uma aprendizagem mais significativa com o público de jovens e adultos. A temática escolhida para a intervenção surgiu a partir das observações feitas na turma, em período anterior a intervenção, onde foi detectada uma problemática passível de ser trabalhada na busca por resultados mais satisfatórios no que diz respeito à construção do conhecimento. A escassez de estudos e relatos de experiência sobre a utilização de materiais didáticos na Educação de Jovens e Adultos influenciou a construção deste trabalho.

O trabalho com recursos didáticos na Educação de Jovens e Adultos se mostra necessário e de fundamental importância, tendo em vista que a 
modalidade necessita de estratégias metodológicas diferenciadas, que promovam significação na aprendizagem e tornem as aulas atrativas e dinâmicas, visando despertar o interesse dos alunos e promover uma aprendizagem significativa (CAVALCANTE; CARDOSO, 2015). Para a construção da temática trabalhada partiu-se dos seguintes pontos: Como os Recursos Didáticos poderão contribuir na aprendizagem dos alunos? Como devem ser utilizados? Qual será a aceitação por parte dos alunos? Nesse contexto, quais as contribuições para a aprendizagem? Quais Recursos Didáticos melhor se adaptam na modalidade de Educação de Jovens e Adultos? Tais questionamentos balizaram as estruturas da intervenção e nortearam a prática pedagógica desenvolvida na sala de aula durante 0 período de Estágio Supervisionado II.

Nesse sentido, o presente artigo tem como objetivo apresentar as contribuições do uso de Recursos Didáticos para o processo de ensino e aprendizagem na Educação de Jovens e Adultos, no $1^{\circ}$ Ciclo, correspondente aos Anos Iniciais do Ensino Fundamental I.

O artigo apresenta a seguinte organização: uma introdução com apresentação do tema, uma revisão teórica com os principais estudos sobre conteúdo abordado, uma seção com a metodologia utilizada para realização do trabalho, uma seção com os resultados e discussões, a seção com as conclusões, e por fim, a seção com as referências utilizadas no trabalho.

\section{REVISÃO TEÓRICA}

A Educação de Jovens e Adultos (EJA) é uma das modalidades de ensino que compõem a Educação Básica no Brasil. A modalidade possui características legislativas e currículo próprio, destinando-se a jovens e adultos que não deram seguimento à Educação Básica na idade apropriada, nessa perspectiva, a EJA orienta-se nos princípios éticos de autonomia, responsabilidade, solidariedade e respeito ao bem comum, nos princípios políticos da cidadania, da criticidade e da democracia, e nos princípios estéticos da sensibilidade, da criatividade, da diversidade das manifestações artísticas e culturais (RONDÔNIA, 2013).

A história da educação para jovens e adultos remonta ao período da colonização, onde foi atribuído aos jesuítas a tarefa de ensinar leitura e escrita para os índios, visando a conversão dos mesmos ao catolicismo (SOUZA, 2007). Ao longo dos anos foram travadas diversas discussões na busca da caracterizar os currículos e as metodologias de ensino na EJA, tendo em vista o leque de especificidades que são inerentes ao público da modalidade. Arroyo (2007, p. 19) aponta que a EJA é um campo aberto de semeaduras e cultivos que nem sempre estiveram bem definidos ao logo da 
trajetória, " é um campo ainda não consolidado nas áreas de pesquisa, políticas públicas e diretrizes educacionais, da formação de educadores e intervenções pedagógicas" dessa forma, depreende-se que a EJA é um espaço em construção e não possui bases sólidas, tendo em vista ainda estar em processo de construção, reformulação e aprimoramento.

Para Di Pierro, Joia e Ribeiro (2001, p.58), "A educação de jovens e adultos é um campo de práticas e reflexão que inevitavelmente transborda os limites da escolarização em sentido estrito. Primeiramente, porque abarca processos formativos diversos [...] e um sem número de questões culturais". Desse modo, percebe-se a teia de complexidades que transitam nas discussões sobre as bases que compõem as atuais práticas de ensino e políticas que constituem a EJA, evidenciando-se um espaço diverso e subjetivo, com processos que transcendem os espaços escolares.

As práticas e métodos de ensino na EJA são um dos pontos mais discutidos por educadores e pesquisadores, em vista da necessidade urgente de se pensar sobre os métodos adequados para abordagem do público de jovens e adultos em todo o país, visando a promoção de uma educação significativa, que forneça os subsídios necessários para o efetivo exercício cidadão.

Muito tem se discutido sobre as metodologias adequadas para 0 trabalho como o público de EJA, no entanto, existem dificuldades no apontamento dessas práticas, uma vez que estas se apresentam de formas diferenciadas para cada realidade que onde são aplicadas. Diante dessa realidade, Cavalcante e Cardoso (2016) pontuam que são imprescindíveis metodologias que enxerguem os educandos como sujeitos históricos, com histórias de vida marcadas pela desigualdade, e diferenciados ritmos de aprendizagem.

O educador necessita conhecer seus alunos, suas expectativas, histórias, sua cultura, sua realidade social e suas necessidades de aprendizagem (BRASIL, 2001). Desse modo, é imprescindível que as metodologias trabalhadas na EJA busquem contemplar essa realidade e conferir significação ao processo de construção do conhecimento, além disso, quando reconhecido dentro de sua realidade, os alunos tendem a diminuir os índices de evasão.

Para Cardoso e Cavalcante (2016) a melhor metodologia que pode ser empregada na EJA é aquela que valorize os conhecimentos prévios dos alunos, suas histórias de vida, suas expectativas de aprendizagem e, atue como meio motivador, que estimule $\mathrm{e}$ incentive os alunos a darem seguimento em suas trajetórias de estudo. Diante dessa realidade, a formação e a especialização docente são aspectos fundamentais para o 
desenvolvimento de um trabalho significativo nas turmas de EJA, além disso, permitem o aperfeiçoamento das práticas e metodologias de ensino.

Os estudos com o público de EJA ao longo dos anos constataram que o perfil do aluno nesta modalidade de ensino está na maioria das vezes relacionado à desigualdade social, a negação de direitos e de oportunidades. Essa realidade tem como consequência a acentuada evasão nas turmas de EJA em todo o país, uma vez que quando retorna ao espaço escolar o jovem/adulto se sente deslocado das séries, e apresenta resistência às metodologias trabalhadas (LEITE; BELO, 2016).

Diante dessa realidade, se faz necessário pensar sobre as metodologias de ensino empregadas na modalidade, na busca de recursos, estratégias didáticas e pedagógicas que permitam conferir maior significação no processo de ensino-aprendizagem na EJA, e dessa forma, reduzir os índices de evasão, ainda tão alarmantes.

Nas séries iniciais do Ensino Fundamental I, os recursos didáticos têm sido visto como estratégias facilitadoras da aprendizagem, pois induzem melhorias na relação professor-aluno, mediação, desenvolvimento cognitivo, socialização das experiências e apropriação significativa do conhecimento trabalhado a partir dos conteúdos escolares (SILVA et al., 2017).

$\mathrm{Na}$ EJA, os recursos didáticos utilizados nas aulas e a metodologia desenvolvida pelo professor podem ser adaptados à realidade das turmas, de modo que permita sua assimilação com cotidiano dos educandos, e desse modo, desperte o interesse destes em participar de forma ativa do processo de ensino-aprendizagem (PAIVA, 2016). A busca por metodologias e linguagem didáticas ativas é uma necessidade que se faz presente na EJA desde sua implementação, pois visam contemplar a diversidade sociocultural de jovens e adultos e incorporá-las nas práticas de ensino desenvolvidas na modalidade (VIEIRA, 2004). Nesse sentido, destaca-se o uso de recursos didáticos como estratégia de ensino e mecanismo facilitador do processo de aprendizagem, ao passo que estimulam o aluno, desenvolvem a sua interação com o professor e permitem maior efetividade no processo de mediação da construção do conhecimento.

Recursos didáticos são condutores de um leque de atividades e visam desenvolver a construção do conhecimento em diversos momentos do processo de ensino-aprendizagem. A reflexão sobre a escolha dos recursos didáticos adequados para o trabalho docente se faz de suma importância, tendo em vista que a escolha adequada pode representar mecanismos facilitadores da aprendizagem, capazes de estimular e enriquecer as experiências na sala de aula e desenvolver a interação professor-aluno (CORDEIRO; BARCELLOS, 2015; SILVA et al.,2017). Segundo Costoldi e Polinarski (2009), os recursos didáticos são fundamentais para o processo de 
desenvolvimento cognitivo do aluno, e devem cumprir a função de aproximar o aluno do conteúdo abordado, promovendo a sua fixação.

Paiva (2016) aponta que os recursos e materiais didáticos na EJA necessitam de serem aperfeiçoados através da prática docente, adaptandoos as peculiaridades dessa modalidade de ensino, pois o recurso utilizado servirá como ponte para a construção do conhecimento, evidenciando que em determinadas situações ele pode até mesmo substituir o professor. A escolha do material a ser utilizado no cotidiano da sala de aula depende da visão do educador acerca do recurso e sua finalidade, além disso, a autora aponta para disponibilidade financeira para a aquisição e a aceitabilidade dos alunos, como fatores que influenciam diretamente no uso e escolha dos recursos didáticos.

Dentre os recursos didáticos mais utilizados, destacam-se: quadro, giz, livros, artigos, músicas, filmes, ilustrações, brincadeiras, jogos, maquetes, entre outros (FERREIRA, 2007). No contexto da EJA, estes devem utilizados de forma que os sujeitos se apropriem da aprendizagem de forma significativa, discutindo e refletindo sobre estes, contextualizado a aprendizagem com o espaço vivido.

Os recursos didáticos que podem ser utilizados nas aulas são os mais diversos, e seus usos sempre estarão associados ao domínio do conteúdo pelo professor, seus objetivos, finalidades e disponibilidades destes. $O$ professor pode optar por adquirir através da compra materiais para confeccionar seus próprios recursos, utilizar os disponíveis no espaço escolar ou mesmo fazer a confecção a partir de material de sucata, é importante destacar que quando o recurso é construindo pelas mão dos próprios alunos estes atribuem significados ao processo e consequentemente terão mais facilidade em trabalhar e alcançar os objetivos propostos com seus usos. Segundo Paiva (2016), na escola existem inúmeros materiais e equipamentos didáticos, alguns criados diretamente para fins didáticos e outros passíveis de serem adaptados para utilização na sala de aula. Seus usos podem estimular a maior percepção visual e auditiva e atribuir significação ao processo de mediação do conhecimento, a escolha de qual usar vai estar relacionada aos objetivos docentes, ao público e as finalidades pedagógicas que já ultrapassam os muros da escola.

\section{METODOLOGIA}

\subsection{Localização}

O município de Esperança está localizado na Mesorregião do Agreste Paraibano e na Microrregião de Esperança, e tem uma população estimada 
em 33.003 habitantes (IBGE, 2010). A Escola Municipal de Ensino Fundamental Francisco Pedro de Oliveira, onde realizou-se o estágio, é uma instituição pública municipal, e está localizada na zona rural do município de Esperança, distando aproximadamente $12 \mathrm{~km}$ da sede municipal (Figura 1). Atualmente o município conta com 25 escolas de Ensino Fundamental e 03 Creches de Educação Infantil, distribuídas entre a zona rural e urbana, tendo o espaço urbano o maior número de instituições com o Ensino Fundamental II.

Figura 1 - Localização da instituição escolar no município de Esperança - PB

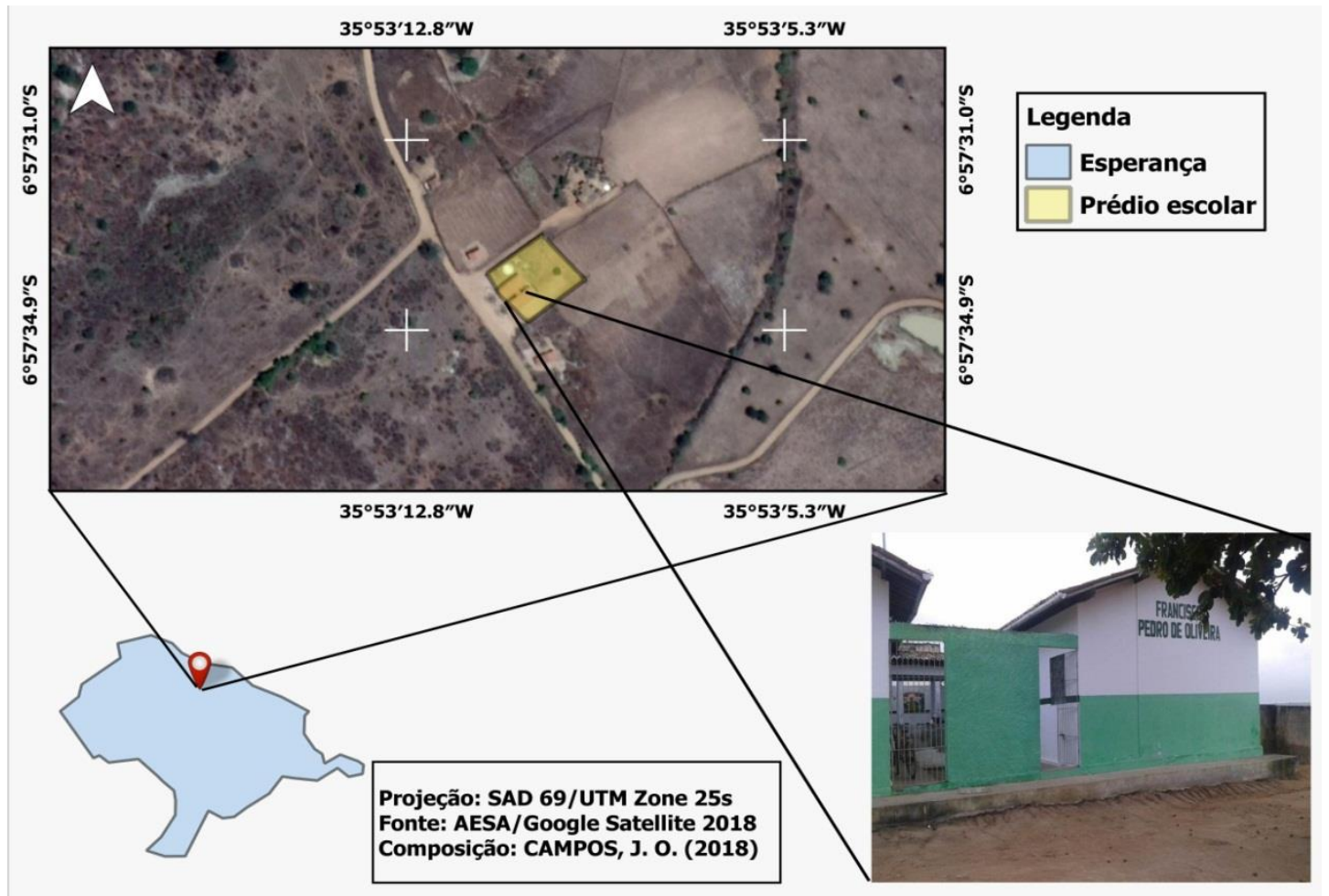

Fonte: Os autores (2018)

A instituição conta com um total de 70 alunos, distribuídos nos seguintes segmentos: Educação Infantil, Ensino Fundamental I e modalidade de Educação de Jovens e Adultos. O público atendido é formado pelos moradores da comunidade onde a escola está inserida e também por alunos de comunidades próximas à localidade. A turma onde foi desenvolvido o estágio é composta por 23 alunos, que frequentam as aulas no horário noturno.

\subsection{Procedimentos Metodológicos}

De início foram assistidas 05 aulas com professor regente, as observações permitiram identificar a necessidade de uma metodologia que 
despertasse o interesse dos alunos, e tornassem as aulas mais dinâmicas e atrativas, tornando mais significativa a aprendizagem dos conteúdos trabalhados nas diferentes áreas do conhecimento. Dessa forma, tais observações levaram a construção de um projeto de intervenção que abordou a utilização de Recursos Didáticos como estratégia metodológica para 0 desenvolvimento da aprendizagem na turma. Para o desenvolvimento das aulas, seguiram-se os seguintes procedimentos: leitura, conversa informativa sobre o conteúdo com os alunos, seguido de sondagem do conhecimento prévio dos mesmos, e contextualização com situações cotidianas, leitura do conteúdo o livro de forma individual ou compartilhada, discussão do conteúdo apresentado pelo livro, considerando as diversas interpretações apresentadas pelos alunos, e por último, a execução das atividades associadas à utilização de um recurso didático.

Os recursos didáticos foram apresentados e utilizados pelos alunos como atividade de fixação do conteúdo e também como suporte para a realização de atividades propostas. Nesse contexto, seus usos foram associados aos conteúdos trabalhados na em sala de aula durante o período do estágio.

\section{RESULTADOS E DISCUSSÕES}

Visando uma maior objetividade na apresentação dos resultados, o período de aulas foi dividido por semanas, e cada conteúdo trabalhado na sala de aula foi associado ao recurso didático utilizado para a execução das atividades propostas. Os materiais didáticos utilizados foram a base para 0 desenvolvimento das atividades propostas em cada um dos conteúdos trabalhados, em alguns casos, o recurso didático também foi utilizado como auxílio na apresentação dos conteúdos.

\subsection{Primeira Semana}

Durante a primeira semana foram trabalhados conteúdos de Matemática, História e Geografia, após a exploração dos conteúdos, os recursos didáticos foram utilizados como meio de fixação da aprendizagem. $\mathrm{Na}$ apresentação dos recursos que seriam utilizados nas aulas os alunos de mostraram interessados em conhecer as formas que seriam aplicados e quais as finalidades. No momento da realização das atividades propostas foi possível observar o interesse dos alunos em desenvolver e alcançar os objetivos propostos. Para utilização dos recursos didáticos apresentados os alunos foram distribuídos em grupos, em decorrência da limitada quantidade dos recursos. Durante $\mathrm{o}$ uso, foram feitas perguntas exploratórias e 
desafiadoras aos alunos, visando estimular a interação e participação. Os alunos se mostraram interessados na participação e foi possível observar que estes se apropriam com mais facilidade dos conceitos trabalhados. Os conteúdo e recursos utilizados estão indicados no Quadro 1.

Quadro 1 - Conteúdos e recursos utilizados na primeira semana

\begin{tabular}{|c|c|}
\hline CONTEÚDO & RECURSO DIDÁTICO \\
\hline Números em forma de fração & Blocos lógicos e material concreto \\
\hline Sinais de trânsito & $\begin{array}{c}\text { Confecção e uso de semáforos com } \\
\text { material reciclado }\end{array}$ \\
\hline Divisão & Grãos de feijão e material dourado \\
\hline Gênero textual: Fábula & Livro didático \\
\hline Árvore genealógica & Árvore genealógica confeccionada \\
\hline
\end{tabular}

Fonte: Os autores (2018)

\subsection{Segunda Semana}

$\mathrm{Na}$ segunda semana foram trabalhados conteúdos de Matemática, Geografia e Português, após a apresentação dos conteúdos e exploração dos mesmos, a turma foi separada em grupos, e em seguida foram distribuídos os recursos, durante a semana, buscou-se agrupar os alunos com mais dificuldades nas atividades com aqueles que apresentaram mais facilidade em realizar as atividades propostas. Como atividade prática foram confeccionadas maquetes na abordagem do tema "lixo", utilizando materiais reciclados na própria instituição (Figura 2).

\section{Figura 2 - Maquete da instituição escolar}

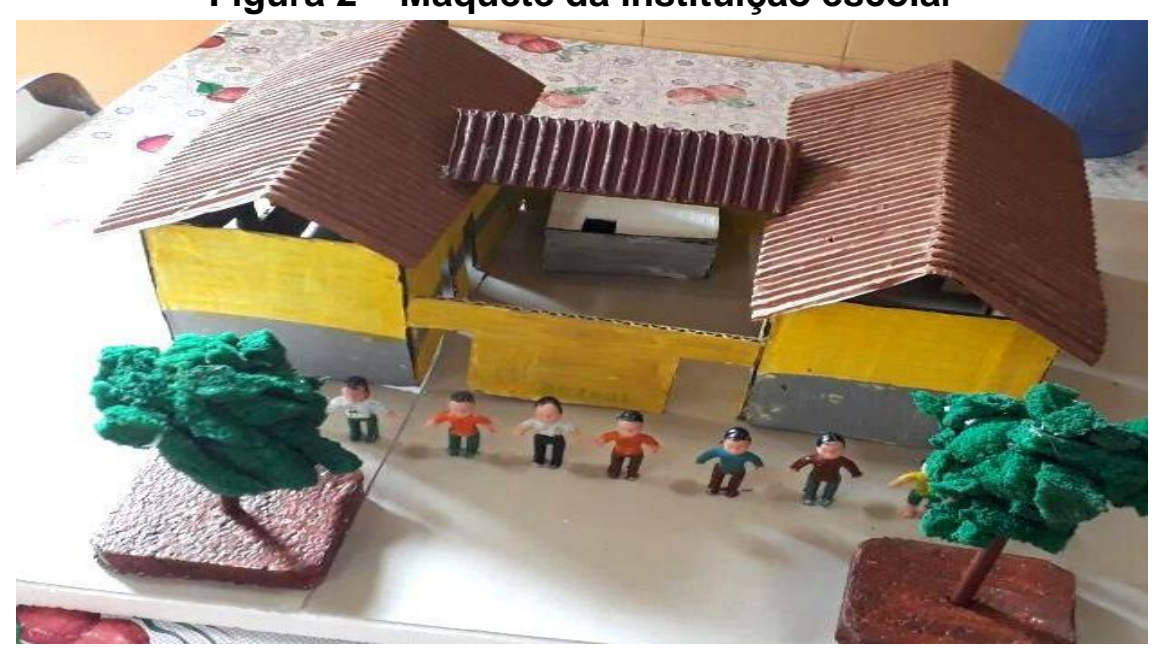

Fonte: Os autores (2018) 
Os alunos demonstram interesse pelas aulas e na realização das atividades práticas com os recursos didáticos utilizados como facilitadores da aprendizagem. Os conteúdos e recursos estão apresentados no Quadro 2.

Quadro 2 - Conteúdos e recursos utilizados na segunda semana

\begin{tabular}{|c|c|}
\hline CONTEÚDO & RECURSO DIDÁTICO \\
\hline Figuras geométricas & Material concreto e material dourado \\
\hline O lixo & $\begin{array}{c}\text { Lixeiras da coleta seletiva } \\
\text { confeccionadas }\end{array}$ \\
\hline Medidas de massa & Balança portátil \\
\hline Sistema Monetário Brasileiro & Cédulas e moedas \\
\hline O uso do til & Cruzadinha e texto lacunado \\
\hline
\end{tabular}

Fonte: Os autores (2018)

\subsection{Terceira Semana}

$\mathrm{Na}$ terceira semana foram abordados conteúdos de Matemática, Português e Ciências, nesta semana, buscou-se diversificar ainda mais os recursos e trazer recursos didáticos diferentes daqueles disponíveis no espaço escolar. A Figura 2 mostra os alunos com o jogo de dominó no trabalho com o conteúdo de adição.

Figura 3 - Utilização do jogo de dominó como recurso didático

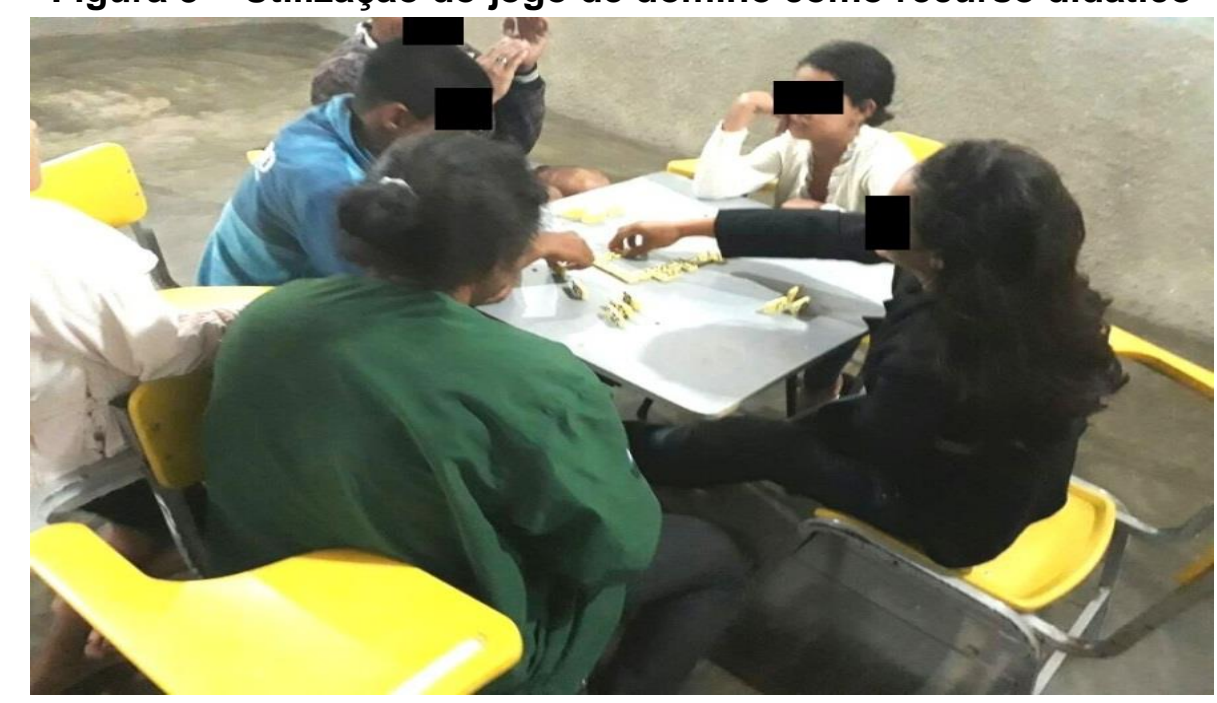

Fonte: Os autores (2018)

Durante a realização das atividades desta semana, os alunos foram desafiados a usar a criatividade e trabalhar os recursos didáticos com base nos conteúdos abordados com base nas orientações do professor. As formas de utilização foram diversificadas e demonstraram o nível de aprendizagem dos alunos em relação aos conteúdos selecionados. Os conteúdos e atividades estão disponíveis no Quadro 3. 
Quadro 3 - Conteúdos e recursos utilizados na terceira semana

\begin{tabular}{|c|c|}
\hline CONTEÚDO & RECURSO DIDÁTICO \\
\hline Adição & Dominó \\
\hline Subtração & Material dourado \\
\hline O uso de r e rr & Cruzadinha \\
\hline Tipos de solos & Imagens \\
\hline Rochas e minerais & Amostras de rochas e minerais do Brasil \\
\hline
\end{tabular}

Fonte: Os autores (2018)

\subsection{Quarta Semana}

$\mathrm{Na}$ quarta e última semana, forma trabalhados conteúdos de Matemática e Português, os recursos didáticos selecionados para abordagem dos conteúdos tiveram ênfase em materiais escritos, diferentes das outras semanas, encontrou-se dificuldades em trabalhar com estes recursos, em razão da necessidade constante de leitura, o que tornou 0 lento 0 desenvolvimento das atividades, no entanto, além de trabalhar os conteúdos, os recursos abordados também contribuíram para o desenvolvimento da leitura e da escrita. Conteúdos e recursos estão indicados no Quadro 4.

Quadro 4 - Conteúdos e atividades utilizados na quarta semana.

\begin{tabular}{|c|c|}
\hline CONTEÚDO & RECURSO DIDÁTICO \\
\hline Calendário & Calendário do ano de 2018 \\
\hline Multiplicação & Cruzadinha \\
\hline Gênero Textual: Cordel & Dramatização de cordel \\
\hline Medidas de tempo & Relógio \\
\hline
\end{tabular}

Fonte: Os autores (2018)

Antes do término das aulas foi feita a socialização das experiências, buscando verificar na opinião dos alunos os pontos fortes e fracos, que são encontrados com o uso dos recursos didáticos. O principal apontamento foi a facilidade de manuseio e uso destes, ajudando a entender os conteúdos, além disso, também apontaram que tiveram maiores dificuldades com os recursos que demandaram leituras mais constantes para realização das atividades com o uso dos recursos disponibilizados

$\mathrm{Na}$ utilização dos recursos didáticos nas aulas os alunos foram motivados a explorar as diversas possibilidades que estes ofereciam, criando e recriando, contextos e situações-problema com base no conhecimento prévio que carregam e no conteúdo trabalhado em sala, tais práticas favoreceram e facilitaram a interação e o diálogo professor-aluno. Como resultado apresentaram maior aprendizagem dos conceitos trabalhados, interesse em realizar as atividades, em participar e em interagir, como 
também verificaram Silva et al. (2017) analisando a experiência de professores com recursos didáticos. Em se tratando dos recursos utilizados, Sousa (2016, p. 49) ressalta que são meios de ampliar a concepção dos alunos sobre os conteúdos escolares e "podem estimular o educando por meio da percepção visual, auditiva ou ambas. O professor poderá usar qualquer tipo de material pedagógico, desde que se analise bem todas as possibilidades de aprendizagem", tal aspecto evidencia a necessidade de se associar o uso desses recursos com o planejamento prévio, buscando oportunizar de forma mais ampla as possibilidades de aprendizagem no conteúdo abordado. Durante a execução das atividades, os alunos interagiram dando sugestões e expondo suas duvidas quando aos procedimentos com os materiais utilizados e aos objetivos propostos com a realização dos exercícios orais, escritos e práticos, conforme também observaram Castoldi e Polinarski (2009) na investigação das contribuições dos recursos pedagógicos para a motivação dos alunos.

A partir da experiência vivenciada depreende-se que os recursos didáticos são ferramentas facilitadoras do processo de aprendizagem, que agem motivando e despertando a curiosidade e estimulando o aluno, para envolver-se nos conteúdos, mesmo naqueles que apresenta maior dificuldade, resultado semelhante foi constatado por Silva et al. (2017) analisando o trabalho com recursos didáticos em uma escola pública. Castoldi e Polinarski (2009) apontam que nessa realidade é de fundamental importância que professor desempenhe o papel de agente motivador da aprendizagem, ao passo que sem a motivação, os recursos didáticos tornamse meras ferramentas visualizadas como formas de ocupar e distrair os alunos.

Nesse sentido, observa-se que as metodologias aplicadas necessitam da intervenção do professor, na figura do agente motivador, que incentiva e enriquece a interação professor-aluno. Em se tratando da EJA, esse papel deve ser desempenhado de forma que 0 aluno sinta-se inserido e protagonista da própria aprendizagem. Arroyo (2007, p. 30), na defesa de uma reconfiguração da EJA, aponta para a necessidade " do reconhecimento da especificidade social e cultural, suas identidades coletivas e de classe, gênero, raça, etnia", em vista disso, tais questões devem ser tomadas como base para as reflexões teóricos-metodológicas que norteiam as práticas de ensino nesta modalidade de ensino, no intuito de contemplar as diversidades que permeiam e são intrínsecas ao processo de ensino-aprendizagem de jovens e adultos. Sobre as metodologias na EJA, Cavalcante e Cardoso (2016) apontam que a melhor metodologia é aquela que valoriza, incentiva e trabalha a autoestima do aluno, fornecendo-lhes subsídios necessários para aprender e seguir com os estudos. 
A partir da análise das atividades realizadas foi possível verificar maior objetividade dos alunos nas respostas, indicando a construção mais significativa dos conceitos presentes nas discussões dos conteúdos que foram selecionados. Tais resultados também foram verificados por Cordeiro e Barcellos (2015) utilizando jogos para abordar os conteúdos das disciplinas em uma turma de EJA no estado do Espirito Santo, demonstrando a eficácia e as possibilidades que estes recursos fornecem quando associados ao planejamento prévio e a realidade das turmas.

Diante os resultados observados chega-se a conclusão que as metodologias que abordam a utilização de recursos didáticos são de fundamental importância para conferir maior significação ao processo de construção do conhecimento, conclusão esta, semelhante a de Silva et al. (2017), pesquisando a importância dos recursos materiais e pedagógicos no processo de aprendizagem na educação básica.

Durante a realização do período do estágio um dos desafios encontrados foi a indisponibilidade de material e recursos didáticos para todos os alunos, de modo que foi necessário separar a turma em grupos em alguns momentos, para dar seguimento com as atividades. A falta de material didático se deu em parte por falta de recursos da escola para a obtenção do mesmo, desse modo a quantidade disponível no espaço escolar encontravase limitada.

Como sugestão para o quadro observado na turma, sugere-se a confecção de recursos didáticos a partir de material de sucata, de forma conjunta, entre professor e aluno, além de representar uma importante etapa da aprendizagem, a confecção desses materiais conduz ao diálogo e a interação entre os alunos, facilitando a socialização e promovendo o trabalho em equipe.

\section{CONCLUSÃO}

O trabalho com recursos didáticos se mostrou eficiente enquanto estratégia metodológica, seus usos constituem um amplo campo de aplicações e abordagens, pois se configuram como ferramenta de auxílio para o desenvolvimento dos conteúdos escolares, em se tratando do Ensino Fundamental I, as possibilidades de uso se espalham pelas diversas áreas do conhecimento e finalidades pedagógicas. A aprendizagem torna-se mais atrativa e o desenvolvimento das atividades torna-se uma prática mais efetiva na construção do conhecimento.

Os recursos que se melhor se adaptaram a realidade da turma onde foi desenvolvida a experiência do estágio foram os recursos materiais, passíveis de serem manejados, com destaque para os jogos e o material concreto. Por 
fornecer maior praticidade, tais recursos tiveram boa aceitação entre os alunos e promoveram maior interação e exploração das possibilidades previstas nas atividades propostas.

O desenvolvimento das atividades tornou-se o momento mais aguardo pelos alunos, o que pode estar relacionado a maior interação entre os mesmos e também ao fato do aluno adulto valorizar as atividades que requerem movimentação, interação, manipulação de objetos e materiais para alcançar objetivos previamente estabelecidos, o que promove uma aprendizagem mais atrativa e prazerosa.

De forma geral os resultados obtidos foram positivos e demonstram a eficiência e contribuições dos Recursos Didáticos utilizados neste trabalho, para 0 processo de ensino-aprendizagem na modalidade EJA, pois os resultados aqui verificados estão em sua maioria de acordo com pesquisas e trabalhos já realizados na área. Além disso, evidenciou a necessidade da reinvenção da prática pedagógica na EJA, na busca por metodologias ativas e significativas, que atuem como facilitadoras do processo de aprendizagem.

Quanto às dificuldades encontradas, destaca-se a indisponibilidade de materiais para a confecção de recursos didáticos que foram utilizados nas aulas e espaços adequados para o trabalho com os alunos, em vista que algumas atividades demandaram espaços mais amplos para melhor execução e resultado. No entanto, tais fatores não chegaram a comprometer o alcance dos objetivos propostos no projeto de intervenção, mas aguçaram e estimularam criatividade docente para contornar essas barreiras e atingir os objetivos.

Como sugestão aponta-se a continuidade do trabalho com recursos didáticos para a construção do conhecimento nas diversas áreas do conhecimento trabalhadas através dos conteúdos escolares. Além disso, se faz necessário o desenvolvimento de novas pesquisas na busca pelo aperfeiçoamento da prática docente e das metodologias de ensino na EJA, evidenciando os pontos fortes e fracos do trabalho com recursos didáticos, no intuito de ampliar as formas de uso e suas aplicações no processo de ensino e aprendizagem.

\section{REFERÊNCIAS}

ARROYO, M. G. Educação de Jovens e Adultos: um campo de direitos e de responsabilidade pública. In: SOARES, L.; GIOVANETTI, M. A. G de C.; GOMES, N. L. G. (Orgs.). Diálogos na Educação de Jovens e Adultos. 2ed., Belo Horizonte: Autêntica, 2007. 
BRASIL. Ministério da Educação. Educação para jovens e adultos: ensino fundamental: proposta curricular. Coordenação e texto final (de) Vera Maria Masagão. São Paulo: Ação Educativa; Brasília: MEC, 2001. 239p

CASTOLDI, R.; POLINARSKI, C. A. A Utilização de Recursos DidáticoPedagógicos na Motivação da Aprendizagem. In: SIMPÓSIO NACIONAL DE ENSINO DE CIÊNCIA E TECNOLOGIA,I, 2009, Ponta Grossa - PR. Anais do I Simpósio Nacional de Ensino de Ciência e Tecnologia - SINECT, Ponta Grossa - PR: UTFPR, 2009, p. 684-692.

Disponível em: < https://atividadeparaeducacaoespecial.com/wpcontent/uploads/2014/09/recursos-didatico-pedag\%C3\%B3gicos.pdf>. Acesso em 20 de Nov. de 2018.

CAVALCANTE, E. dos S. L.; CARDOSO, M. A. Reflexões sobre a metodologia utilizada na Educação de Jovens e Adultos: entre 0 real e 0 ideal. Revista Lugares de Educação [RLE], Bananeiras-PB, v. 6, n. 12, p.158-181, Jan.-Jul., 2016.

Disponível

em:

http://www.periodicos.ufpb.br/ojs/index.php/rle/article/view/23979>. Acesso em 10 de Out. de 2018.

CORDEIRO, K. M. dos. S.; BARCELLOS, W. de S. O uso de jogos pedagógicos na Educação de Jovens e Adultos. Revista Científica Interdisciplinar, vol. 2, n.4, p. 222-232, Out./Dez., 2015

DI PIERRO, M. C.; JOIA, O. RIBEIRO, V. M. Visões da Educação de Jovens e Adultos no Brasil. Cadernos Cedes, v. 21, no 55, p. 58-77, nov., 2001. Disponível em: < http://www.scielo.br/pdf/ccedes/v21 n55/5541.pdf>. Acesso em 10 de Set. de 2018.

FERREIRA, S.M.M. Os recursos didáticos no processo de ensinoaprendizagem: estudo de caso da escola secundária Cónego Jacinto. 2007. 69 f. Monografia (Bacharelado em Ciências da Educação e Praxis Educativa) - Universidade Jean Piaget de Cabo Verde, Grande Cidade da Praia, Santiago, Cabo Verde. 2007.

IBGE - Instituto Brasileiro de Geografia e Estatística. Panorama: Esperança, 2010.

Disponível em: < https://cidades.ibge.gov.br/brasil/pb/esperanca/panorama> Acesso em 20 de Nov. de 2018. 
LEITE, N. da C. BELO, A. L. M. A importância da ludicidade na educação de jovens e adultos: um estudo numa escola pública no município de Macapá/AP. Faculdade Atual, Macapá - AP, 2016.

Disponível em: < https://www.monografias.com/pt/trabalhos3/importancialudicidade-educacao-jovens-adultos/importancia-ludicidade-educacao-jovensadultos2.shtml>Acesso em 25 de Nov. de 2018.

PAIVA, C. de L. C. Material didático na Educação de Jovens e Adultos: Avaliação dos Mediadores de Leitura do Município de Conde-PB. 2016. 38f. (Monografia de Graduação) Universidade Federal da Paraíba - UFPB, João Pessoa, 2016.

RONDÔNIA. Secretaria de Estado da Educação. Educação de Jovens e Adultos - EJA: ensino fundamental e ensino médio, 2013.

Disponível em: < http://www.seduc.ro.gov.br/curriculo/wpcontent/uploads/2013/02/EDUCACAO-DE-JOVENS-E-ADULTOS-EJA.pdf>

Acesso em 20 de Nov. de 2018

SILVA, A. C. M.; FREITAG, I. H.; TOMASELLI, M. V. F. BARBOSA, C. P. A importância dos recursos didáticos para o processo ensino-aprendizagem. Arquivos do MUDI, v 21, n 02, p. 20-31, 2017.

Disponível em: $<$ http://periodicos.uem.br/ojs/index.php/ArqMudi/article/view/38176>. Acesso em 22 de Out. de 2018.

SOUSA, E. S. de O. S. Prática pedagógica e o uso dos recursos didáticos na EJA: um estudo em uma escola municipal de Porto Velho-RO. 2016. 79f. Monografia de TCC (Curso de Pedagogia). Departamento de Ciências da Educação. Fundação Universidade Federal de Rondônia, Porto Velho - RO, 2016.

SOUZA, M. A. Educação de jovens e adultos. Curitiba: IBPEX, 2007.

VIEIRA, M. C. Fundamentos históricos, políticos e sociais da educação de jovens e adultos. Volume I: aspectos históricos da educação de jovens e adultos no Brasil. Universidade de Brasília, Brasília, 2004. 